\title{
An optimization technique for cropping patterns and land consolidation: A case study for irrigation network
}

\author{
Azim Shirdeli* and Somayeh Dastvar
}

Department of Civil Engineering, University of Zanjan, Zanjan, Iran

CHRON I CLE A B S TRACT

Article history:

Received March 202014

Accepted 28 July 2014

Available online

August 82014

Keywords:

Irrigation

Agriculture

Irrigation

\section{Introduction}

During the past few decades, there has been growing interest in water resources management (Esat \& Hall, 1994; Lindenmaier et al., 2003; Colbach, 2010). There are several reasons for having water shortage for agricultural activities such as growth of population (Vasseur et al., 2013), global warming (Yang et al., 2011; Waha et al., 2013; Matthews et al., 2013). Presently, there are many areas in Middle East facing with shortage of water for agricultural activities (Kangrang \& Compliew, 2010). According to Long et al. (2014), farmers must implement an assortment of management practices to ensure the sustainability, economic viability, and resilience of their operation. According to Aghajani et al. (2013), augmenting or limiting cultivation of agricultural crops in various areas could be accomplished by considering different constraints and availability of fertile agricultural land. They performed an optimization technique and reported that optimum cropping pattern could increase the total profit of regions in Iran, significantly. Mirkarimi et al. (2013) proposed a fuzzy goal

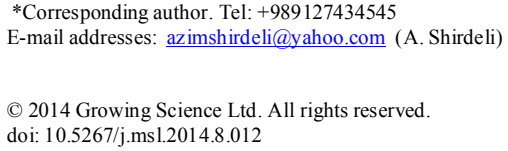


programming for optimizing cropping patterns under three scenarios and found that their proposed model could significantly increase the profit of agricultural program.

Mihara (1996) studied the effects of agricultural land consolidation on erosion processes in semimountainous paddy fields of Japan. Thomas (2006) performed a survey on property rights, land fragmentation and the emerging structure of agriculture in Central and Eastern European countries. Alabdulkader et al. (2012) presented a model to optimize the cropping pattern in Saudi Arabia to maximize the net annual return of the agricultural sector in the country and ensuring the efficient allocation of the scarce water resources and arable land among the competing crops. They reported a potential for Saudi Arabia to maximize its cropping pattern and to build an estimated net return equivalent to about 2.42 billion US \$ per year. The optimized cropping pattern in Saudi Arabia was coupled with about $53 \%$ saving in water consumption and about $48 \%$ reduction in the arable land consumption compared with the base-year cropping pattern. Comparable weights was devoted to various crop groups by allocating about $48.4 \%, 35.4 \%, 13.1 \%$, and $3.2 \%$ to grow cereals, fruits, forages, and vegetables, respectively.

Dariane and Hughes (1991) developed a model for real-time operation of an irrigation reservoir with the objective of maximizing the value of multiple crop yields during a growing season. Their model used monthly additive and product forms of crop yield functions for dry matter and grain crops, respectively. They claimed that the proposed model results had been better in terms of net benefits from crop yields. Dury et al. (2013) presented an analysis of farmer cropping-plan decision-making. They surveyed 30 farmers to investigate the dynamics of their cropping-plan decision-making on irrigated arable farms. They analyzed the ways farmers managed uncertainty through planning and reactive decisions and reported that representing cropping plan selection only as a resource-allocation or crop-rotation-design problem would not be enough to account for farmers' decision-making processes. They explained that cropping-plan decision making would not happen once per year or per rotation, as is usually represented in models, but is a continuous process mixing design and adaptive activities.

\section{The proposed study}

In this section, we present mathematical model to determine the amount of land for cultivating different products and the amount watering each product in order to maximize total profit. Let $p$ be the index of each product, $c_{p}$ be the selling price of product $p, s_{p}$ be the area of land, which is devoted for product $p$. In our survey, each product has a specific yield $y_{p}, w_{r}(p, t)$ and $w_{d}(p, t)$ be the amount of water assigned and the amount of devoted water for product $p$ at time $i$, respectively. Finally, let $l(p, t)$ be the amount of water stress for product $p$ at time $t$. The proposed study of this paper maximizes the following objective function,

$$
\max z=\sum_{p=1}^{n} c_{p} s_{p} y_{p} \prod_{t=1}^{T}\left[\frac{w_{r}(p, t)}{w_{d}(p, t)}\right]^{l(p, t)} .
$$

There are two constraints associated with the proposed study of this paper. The first constraints specifies the limit on the amount of land devoted to all products as follows,

$\sum_{p=1}^{n} s_{p} \leq s_{0}$

where $s_{0}$ is the total amount of available land to be given to all products. In addition, we consider the following constraint for the amount of water specified to all products. 
$\sum_{p=1}^{n} w_{r}(p, t) \leq w_{0}(t)$

where $w_{0}(t)$ represents total amount of water, which could be specified to all products. As we can observe from the results of the mathematical model, there are two types of variables, $s_{p}$ and $w_{r}(p, t)$.

\section{Case study}

The city of Abhar is a county in Zanjan Province in Iran. The capital of the county is Abhar and at the 2006 census, the county's population was 158,544, in 41,333 families. Abhar in the southeastern city of Zanjan in the range of 49 degrees 12 minutes east longitude and 36 degrees 11 minutes north. The city has an area of 3,200 square kilometers and the average elevation of 1550 meters above sea level. This city includes of four regions of Abhar, Soltanieh, Sayyn castle and Hydj. There are some efforts to build some dams to provide necessary water supply for agricultural product. Fig. 1 also shows Cadastral maps for Boein coastal dams before integration and the development of agriculture.
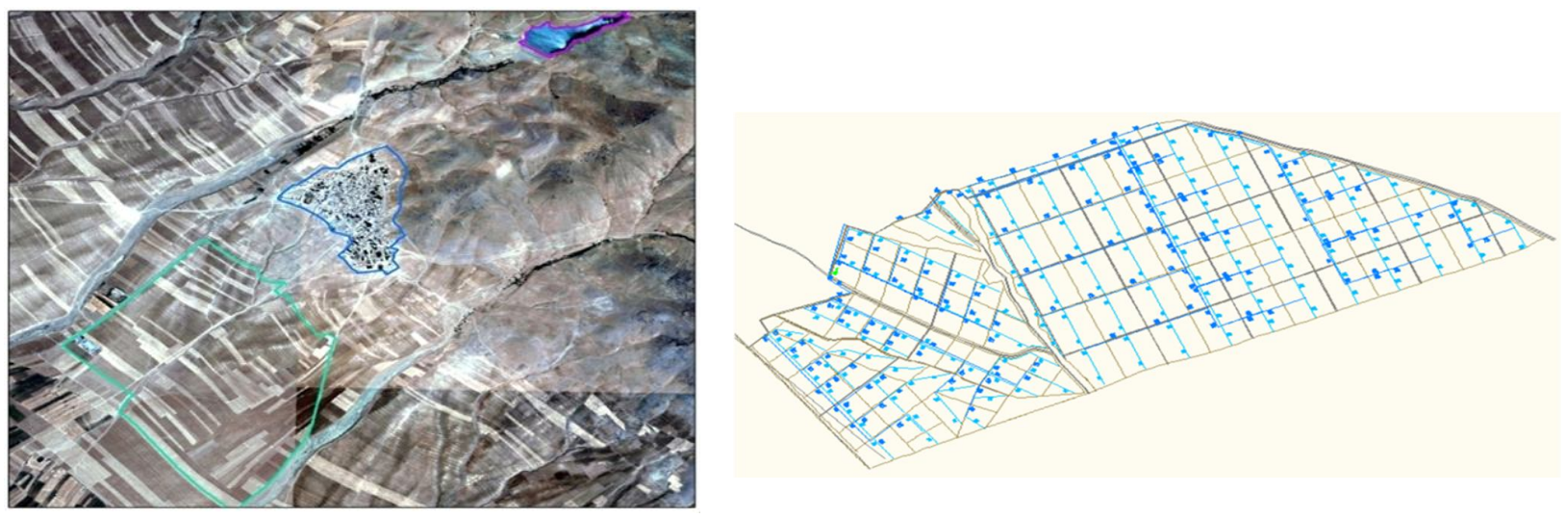

Fig. 1. Satellite photo of Cadastral maps Boein coastal dams before integration and the development of agriculture

There are two types of dry and land farming. Table 1 demonstrates the maximum amounts of products produced.

\section{Table 1}

The maximum amount of products obtained based on two systems in terms of kilogram per hectare

\begin{tabular}{llcc}
\hline Item & Product & Land farming & Dry farming \\
\hline 1 & Grain & 8200 & 1185 \\
2 & Corn & 65000 & - \\
3 & Potato & 64500 & - \\
4 & Wheat & 8324 & 1850 \\
5 & Beans & 4435 & - \\
6 & Hay & 8700 & 1339 \\
7 & Lentils & - & 500 \\
9 & Peas & 450 & - \\
10 & Tomato & 85000 & - \\
11 & Apple & 94998 & - \\
12 & Peach & 5962 & - \\
13 & Grapes & 44998 & - \\
14 & Nuts & 5300 & - \\
\hline
\end{tabular}

In addition, Table 2 demonstrates the amount of water flow in each month for each product. 
Table 2

The amount of water flow needed for each product in term of thousand cubic meter per hectare

\begin{tabular}{lcccccccccccc}
\hline Month & March & April & May & June & July & August & September & October & November & December & January & February \\
\hline Grain & 0.57 & 0.82 & 0.37 & 0 & 0 & 0 & 0 & 0 & 0 & 0 & 0 & 0.14 \\
Corn & 0 & 0 & 0.61 & 1.76 & 1.8 & 1.05 & 0 & 0 & 0 & 0 & 0 & 0 \\
Potato & 0 & 0.19 & 1.31 & 1.88 & 1.77 & 1.12 & 0 & 0 & 0 & 0 & 0 & 0 \\
Wheat & 0.57 & 0.89 & 0.84 & 0 & 0 & 0 & 0.06 & 0 & 0 & 0 & 0 & 0.14 \\
Beans & 0 & 0 & 0.53 & 1.59 & 1.77 & 0.88 & 0 & 0 & 0 & 0 & 0 & 0 \\
Hay & 0.63 & 0.97 & 1.78 & 2.145 & 2.06 & 1.54 & 0.98 & 0.29 & 0 & 0 & 0 & 0 \\
Lentils & 0 & 0.66 & 1.55 & 0.7 & 0 & 0 & 0 & 0 & 0 & 0 & 0 & 0 \\
Peas & 0 & 0.66 & 1.55 & 0.7 & 0 & 0 & 0 & 0 & 0 & 0 & 0 & 0 \\
Tomato & 0 & 0 & 0.96 & 2.12 & 2.11 & 1.1 & 0 & 0 & 0 & 0 & 0 & 0 \\
Apple & 0 & 0.26 & 1.17 & 1.42 & 1.35 & 0.55 & 0 & 0 & 0 & 0 & 0 & 0 \\
Peach & 0 & 0.08 & 1.27 & 1.6 & 1.51 & 1.19 & 0.19 & 0 & 0 & 0 & 0 & 0 \\
Grapes & 0 & 0.6 & 1.54 & 1.85 & 1.75 & 1.38 & 0.19 & 0 & 0 & 0 & 0 & 0 \\
Nuts & 0 & 0.52 & 1.25 & 1.51 & 1.44 & 0.93 & 0 & 0 & 0 & 0 & 0 & 0 \\
\hline
\end{tabular}

The implementation of the proposed study based on the information given in Table 1 and Table 2 . The results of the optimal amount of land and water devoted to two types of dry and land farming and the results are given in Table 3. The optimal solutions are provided in terms of four phases of an economic program as well as some basic plan.

Table 3

The optimal solution

\begin{tabular}{lccccccccccc}
\hline & \multicolumn{2}{c}{ Phase 1 } & \multicolumn{2}{c}{ Phase 2 } & \multicolumn{2}{c}{ Phase 3 } & \multicolumn{2}{c}{ Phase 4 } & \multicolumn{3}{c}{ Basic } \\
\cline { 2 - 11 } & Land & Dry & Land & Dry & Land & Dry & Land & Dry & Land & Dry \\
\hline Grain & 12.57 & 19.61 & 5.8 & 20.11 & 4.35 & 20.61 & 3.62 & 11.21 & 6.57 & 7.12 \\
Corn & 0 & 0 & 0 & 0 & 0 & 0 & 4.62 & 0 & 2.89 & 0 \\
Potato & 8.29 & 0 & 8.48 & 20.11 & 8.67 & 0 & 4.71 & 0 & 5.26 & 0 \\
Wheat & 8.29 & 19.61 & 8.48 & 0 & 8.67 & 20.61 & 4.71 & 60.71 & 18.4 & 88.54 \\
Beans & 8.29 & 0 & 8.48 & 20.11 & 8.67 & 0 & 4.71 & 0 & 15.77 & 0 \\
Hay & 8.29 & 19.61 & 8.48 & 20.11 & 8.67 & 20.61 & 12.39 & 11.21 & 20.24 & 0.33 \\
Lentil & 8.29 & 19.61 & 8.48 & 20.11 & 8.67 & 20.61 & 4.61 & 11.21 & 0 & 2.45 \\
Peas & 8.29 & 19.61 & 8.48 & 0 & 8.67 & 20.61 & 4.61 & 11.21 & 0 & 1.56 \\
Tomat & 8.29 & 0 & 8.48 & 0 & 8.67 & 0 & 4.71 & 0 & 3.61 & 0 \\
Apple & 8.29 & 0 & 8.48 & 0 & 8.67 & 0 & 4.71 & 0 & 19.41 & 0 \\
Peach & 12.3 & 0 & 19.64 & 0 & 21.67 & 0 & 52.56 & 0 & 5 & 0 \\
Grape & 8.29 & 0 & 8.48 & 0 & 8.67 & 0 & 4.7 & 0 & 2.55 & 0 \\
Nuts & 8.29 & 0 & 8.48 & 0 & 8.67 & 0 & 4.71 & 0 & 7.69 & 0 \\
\hline
\end{tabular}

\section{Discussion and conclusion}

Being situated in arid and semi-arid climate, has manifested water as the most limiting and important factors of production in many agricultural parts of Iran. Small agricultural lands, improper irrigation and drainage techniques, inefficient cropping pattern and water allocation with other similar problems, are major barriers for increasing agricultural production in Iran. In this paper, we have presented an optimization technique for increasing water use efficiency in agricultural systems. The proposed study has gathered some information such as satellite imagery and cadastral maps with available data and information such as cultivated area, yield and price for irrigated and rain-fed crops in Abhar District, Zanjan province. In addition, the impacts of agricultural land consolidation and optimal cropping pattern on cultivated area and water use efficiency, as well as water productivity and farmers' gross income have been investigated. The results of our survey have indicated that the amount of water used in the city for agricultural program presently has reached to 422 million cubic 
meters. According to the results of Table 3, the farmers' income will substantially increase when the mathematical model has been implemented for optimally using land for special products. The efficiency of water consumption for agricultural products can be increased from $50 \%$ to $76 \%$. In addition, total incomes of the farmers have increased by $250.34 \%$ and $7.27 \%$ of the agricultural lands would be increased when the plan is completely implemented.

\section{Acknowledgement}

The authors would like to thank the anonymous referees for constructive comments on earlier version of this paper.

\section{References}

Aghajani, A., Bidabadi, F. S., Joolaei, R., \& Keramatzadeh, A. (2013). Managing cropping patterns agricultural crops of three counties of Mazandarn province of Iran. International Journal of Agriculture and Crop Sciences, 5(6), 596-602.

Alabdulkader, A. M., Al-Amoud, A. I., \& Awad, F. S. (2012). Optimization of the cropping pattern in Saudi Arabia using a mathematical programming sector model. Agricultural Economics (Zemédělská Ekonomika), 58(2), 56-60.

Colbach, N. (2010). Modelling cropping system effects on crop pest dynamics: how to compromise between process analysis and decision aid. Plant Science,179(1), 1-13.

Dariane, A. B., \& Hughes, T. C. (1991). Application of crop yield function in reservoir operation. Journal of the American Water Resources Association, 27(4), 649-656.

Dury, J., Garcia, F., Reynaud, A., \& Bergez, J. E. (2013). Cropping-plan decision-making on irrigated crop farms: A spatio-temporal analysis. European Journal of Agronomy, 50, 1-10.

Esat, V., \& Hall, M. J. (1994, September). Water resources system optimization using genetic algorithms. In Hydroinformatics (Vol. 94, pp. 225-231).

Kangrang, A., \& Compliew, S. (2010). An application of linear programming model for planning dry-seasonal irrigation system. Trends in Applied Sciences Research, 5(1), 64-70.

Lindenmaier, F., Zehe, E., \& Ihringer, J. (2003). Impact of land consolidation on flood formation in small catchments. In EGS-AGU-EUG Joint Assembly, 1, 8412.

Long, J. A., Lawrence, R. L., Miller, P. R., \& Marshall, L. A. (2014). Changes in field-level cropping sequences: Indicators of shifting agricultural practices. Agriculture, Ecosystems \& Environment, 189, 11-20.

Matthews, R. B., Rivington, M., Muhammed, S., Newton, A. C., \& Hallett, P. D. (2013). Adapting crops and cropping systems to future climates to ensure food security: The role of crop modelling. Global Food Security, 2(1), 24-28.

Mihara, M. (1996). Effects of agricultural land consolidation on erosion processes in semimountainous paddy fields of Japan. Journal of Agricultural Engineering Research, 64(3), 237247.

Mirkarimi, S. H., Joolaie, R., Eshraghi, F., \& Abadi, F. S. B. (2013). Application of fuzzy goal programming in cropping pattern management of selected crops in Mazandaran province: Case study of Amol township. International Journal of Agriculture and Crop Sciences, 6(15), 10621067.

Thomas, J. (2006). Property rights, land fragmentation and the emerging structure of agriculture in Central and Eastern European countries. Electronic Journal of Agricultural and Development Economics Food and Agriculture Organisation, Rome: eJADE, 3(2), 225-275.

Vasseur, C., Joannon, A., Aviron, S., Burel, F., Meynard, J. M., \& Baudry, J. (2013). The cropping systems mosaic: How does the hidden heterogeneity of agricultural landscapes drive arthropod populations?. Agriculture, Ecosystems \& Environment, 166, 3-14.

Yang, X. G., Liu, Z. J., \& Chen, F. (2011). The possible effect of climate warming on northern limits of cropping system and crop yield in China. Agricultural Sciences in China, 10(4), 585-594. 
Waha, K., Müller, C., Bondeau, A., Dietrich, J. P., Kurukulasuriya, P., Heinke, J., \& Lotze-Campen, H. (2013). Adaptation to climate change through the choice of cropping system and sowing date in sub-Saharan Africa. Global Environmental Change, 23(1), 130-143. 